\title{
Management and Prevention of Leakage after Sleeve Gastrectomy
}

\author{
Ahmed H. Diab ${ }^{1, *}$ MB BCh, Atef M. El Mahdi ${ }^{2}$ MD \& Mohamed H. El Kaseer ${ }^{2}$ MD
}

\author{
* Corresponding Author: \\ Ahmed H. Diab \\ ahmedhdiab515@gmail.com
}

Received for publication
September 16, 2020; Accepted
December 30, 2020; Published online December 30, 2020.

\section{Copyright 2020 The Authors published by Al-Azhar University, Faculty of Medicine, Cairo, Egypt. All rights reserved. This an open-access article distributed under the legal terms, where it is permissible to download and share the work provided it is properly cited. The work cannot be changed in any way or used commercially. \\ doi: $10.21608 /$ aimj.2020.40898.1314 \\ 1 General Surgery Department, Shebin ElKom teaching hospital, Egypt. \\ ${ }^{2}$ General Surgery Department, Faculty of Medicine, Al-Azhar University, Cairo, Egypt.}

\begin{abstract}
Background: Sleeve gastrectomy (SG) is currently the most commonly performed bariatric surgery. Postoperative leak is one of the most serious complications. Knowledge of the clinical presentation, together with the postoperative anatomy is crucial for the prevention, early diagnosis and proper management of this potentially life-threatening complication.

Aim of work: The aim of this study was to determine the lines of management and outcomes of leakage after sleeve gastrectomy.

Patient and methods: Morbid obese patients (BMI > 35) with associated comorbidities such as sleep apnea, hypertension and/or type 2 diabetes were included in the study. Morbid obese patients (BMI > 40) who are at increased risk of health problems were also recruited. Data was collected from medical records including age, sex, BMI, preoperative comorbidities, operative findings, postoperative follow up, the interval between surgery and leak, in addition to the onset and site of leak, management lines and outcomes.

Results: The study included 20 patients. Half (50\%) of patients showed intra-operative positive leak test and required stable line reinforcement. Postoperative follow up revealed leak in all (100\%) of patients. First line management of leak was laparoscopic abscess drainage (30\%), bleeding control (30\%), Pigtail drainage (20\%), and fistula repair and reinforcement $(20 \%)$. The most common reported complications of leak management were failure of 1 st line management $(90 \%)$, stent migration in $3(15 \%)$, stent related ulcer and stricture in $1(5 \%)$ each.

Conclusion: Based on these findings, it could be concluded that most cases of gastric leak after SG could be successfully managed by endoscopic esophageal mega stent. However, persistent chronic leak is a serious complication associated with prolonged hospitalization, cost, and unfavorable outcomes.
\end{abstract}

Keywords: Sleeve Gastrectomy; Gastric Leak; Diagnosis; Treatment; Outcomes.

Disclosure: The authors have no financial interest to declare in relation to the content of this article. The Article Processing Charge was paid for by the authors.

Authorship: All authors have a substantial contribution to the article.

\section{INTRODUCTION}

Currently, sleeve gastrectomy (SG) is the most commonly performed bariatric surgery. It involves reduction of the stomach to about $20 \%$ of its original size to induce satiety and reduce appetite. ${ }^{1}$ It is safe and effective procedure for the management of morbid obesity associated with comorbid conditions. However, it is not free of complications especially in risky patients. ${ }^{2}$

Postoperative leak is one of the most serious complications of SG. According to the United Kingdom Surgical Infection Study Group, anastomotic leakage is defined as "the leak of luminal contents from a surgical join among two hollow viscera".

The frequency of gastric leakage after SG ranging from 1.1 to $5.3 \%{ }^{4}$ Though this complication is uncommon, it is still considered as the second cause of death after SG, with an overall reported mortality rate $0.4 \% .^{5}$
Postoperative gastric leak may be due to mechanical or ischemic causes. Mechanical factors include using staplers with inappropriate firing in addition to the possible direct traumatic tissue injury. Alternatively, ischemia of the upper part of the staple line near the gastroesophageal junction can explain this common location of leak. A true or function distal gastric outflow obstruction can precipitate proximal leak.,

Gastric leak may remain a symptomatic and detected only through radiological examination or becomes symptomatic. Clinical manifestations include abdominal pain, vomiting, fever, tachypnea, and tachycardia. ${ }^{8}$ Sustained tachycardia has been reported as the most common early warning clinical sign that necessitate further investigations. ${ }^{9}$

Therapeutic approaches of postoperative leak vary depending on its onset and the condition of the patient. A conservative strategy is supported in stable patients while, hemodynamically unstable patients require surgical 
intervention in which primary repair of leak or just washout and drain placement is performed. Recently, the use of stents for managing acute proximal leakage was established as a valid treatment option. ${ }^{1}$

Knowledge of the clinical presentation, together with the postoperative anatomy is crucial for the prevention, early diagnosis, and proper management of this potentially lifethreatening complication. ${ }^{7}$ Currently, there is a lack of an internationally approved algorithm for leak management. ${ }^{10}$

Therefore, the aim of this study was to determine the lines of management and outcomes of leakage after sleeve gastrectomy.

\section{PATIENT AND METHODS}

Design, setting, ethical considerations:

This retrospective study was carried out at Al-Azhar university hospitals and Shebin El-Kom teaching hospital after ethical approval from Faculty of medicine, Al-Azhar University. It included 20 patients who fulfilled the eligibility criteria and gave an informed decision to have SG and who were complicated by leakage. Their data was maintained confidential by making code number for everyone.

\section{Eligibility criteria:}

Inclusion criteria

Morbid obese patients (BMI > 35) with associated comorbidities such as sleep apnea, hypertension and/ or type 2 diabetes or morbid obese patients (BMI $>40$ ) who are at increased risk for health problems. All participants must have tried to lose weight in a documented, formalized weight control program and willing and motivated to make permanent life style changes necessary to live a healthier life.

\section{Exclusion criteria}

Patients had bad general condition in the form of severe anemia, hypoalbuminemia, electrolyte imbalance, immunocompromised and/or elderly were excluded. Additionally, other exclusion parameters included presence of local gastric factors as hiatus hernia, atrophic gastritis, and gastric ulcers, besides the presence of other causes of leakage as traumatic or pathologic causes, leakage after other bariatric operations as laparoscopic adjustable gastric banding, gastric bypass, and Leakage after other gastric operations as partial gastrectomy.

Methods:

The following data were collected; age, sex, BMI, preoperative comorbidities, operative findings, postoperative follow up, the interval between the surgery and leak and the onset and site of leak, management lines and outcomes.

According to the condition of the patient and the time of leak, management of postoperative leak involved prompt surgical intervention, lavage, drainage and over sewing for early detected leak in stable patients. Intermediate and late leakage in stable patients were treated by conservative management, if improved continue the same approach, but if not improved, endoscopic prosthesis trial with further removal after 6 - 8 weeks or surgical management were performed. If still no improvement, Roux-en-Y gastrojejunostomy or total gastrectomy was done. Unstable patients were treated by prompt surgical management.

\section{Statistics:}

An Excel spreadsheet was established for the entry of data. Validation checks on numerical variables and option-based data entry method for categorical variables were used to reduce potential errors. The analyses were carried with SPSS software (Statistical Package for the Social Sciences, version 24, SSPS Inc., Chicago, IL, USA). The normality of data was assessed using Shapiro-Wilk Test. Numerical data were described as mean $\pm \mathrm{SD}$ if normally distributed; or median and interquartile range [IQR] if not normally distributed. Frequency tables with percentages were used for categorical variables. A pvalue $<0.05$ was considered statistically significant.

\section{RESULTS}

The study included 20 patients who underwent laparoscopic SG bariatric surgery and developed postoperative leak. The majority $(70 \%)$ of the study participants were females. The mean age was 30.5 \pm 7.5 years and the mean BMI was $43.13 \pm 4.6$. Diabetes mellitus (25\%) and dyslipidemia and gout (20\%) were the most frequent comorbidities. Figure (1) illustrates comorbidities of the studied patients. Diabetes mellitus and dyslipidemia in addition to gout were the most frequent $(25 \%$ and $20 \%$ respectively).

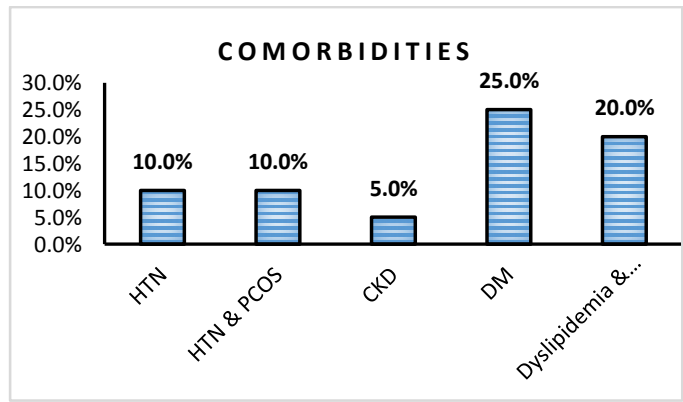

Fig. 1: Co-morbidities

Table (1) demonstrates operative findings and postoperative follow up. Half $(50 \%)$ of patients showed positive leak test and required stable line reinforcement while, 9 (45\%) developed bleeding during the operation. Postoperative follow up revealed leak in all (100\%) of patients and bleeding in $30 \%$ of them. 


\begin{tabular}{|c|c|}
\hline Variables & $\begin{array}{l}\text { Patients } \\
(\mathbf{N}=\mathbf{2 0})\end{array}$ \\
\hline \multicolumn{2}{|l|}{ Operative findings, No (\%) } \\
\hline - $\quad$ Bleeding & $9(45 \%)$ \\
\hline - $\quad$ Adhesion & $3(15 \%)$ \\
\hline $\begin{array}{ll}- & \text { Positive leak test }\end{array}$ & $4(20 \%)$ \\
\hline Reinforcement & $10(50 \%)$ \\
\hline \multicolumn{2}{|l|}{ Post-op follow up, No (\%) } \\
\hline - $\quad$ Bleeding & $6(30 \%)$ \\
\hline - $\quad$ Leak & $20(100 \%)$ \\
\hline
\end{tabular}

Table 1: Demonstrates operative findings and pot-op follow up.

The interval between surgery and leak ranged from 1 to 15 days with a median of 4 days. Early leak was the most frequent followed by intermediate and late ones $(80 \%, 15 \%$, and $5 \%$ respectively). The site of leak was most commonly at GEJ (50\%) or beyond it $(25 \%)$ while, $4(20 \%)$ cases developed leak at incisura angularis (Table 2).

\begin{tabular}{|c|c|}
\hline Variables & $\begin{array}{l}\text { Patients } \\
(\mathrm{N}=\mathbf{2 0})\end{array}$ \\
\hline \multicolumn{2}{|c|}{ Interval between surgery and leak in days } \\
\hline - $\quad$ Mean \pm SD & $4.1 \pm 2.9$ \\
\hline - $\quad$ Median (Range) & $4(1-15)$ \\
\hline \multicolumn{2}{|l|}{ Time of Leak, No (\%) } \\
\hline - $\quad$ Early & $16(80 \%)$ \\
\hline - Intermediate & $3(15 \%)$ \\
\hline - $\quad$ Late & $1(5 \%)$ \\
\hline \multicolumn{2}{|l|}{ Leak site, No (\%) } \\
\hline - $\quad$ GE junction & $10(50 \%)$ \\
\hline - $\quad$ Beyond GE junction & $5(25 \%)$ \\
\hline - $\quad$ At incisura angularis & $4(20 \%)$ \\
\hline - $\quad$ No obvious site & $1(5 \%)$ \\
\hline
\end{tabular}

Table 2: Characteristics of the leak of the included ptients.

First line management of leak was in the form of laparoscopic abscess drainage (30\%), bleeding control $(30 \%)$, Pigtail drainage $(20 \%)$, and fistula repair and reinforcement (20\%). These interventions failed in $18(90 \%)$ cases and $2(10 \%)$ cases were completely cured as illustrated in table (3).

\begin{tabular}{|c|c|}
\hline Variables & $\begin{array}{c}\text { Patients } \\
(\mathrm{N}=\mathbf{2 0})\end{array}$ \\
\hline \multicolumn{2}{|l|}{ First-line, No (\%) } \\
\hline - $\quad$ Pigtail drainage & $4(20 \%)$ \\
\hline $\begin{array}{ll}- & \begin{array}{l}\text { Fistula repair } \\
\text { reinforcement }\end{array}\end{array}$ & $4(20 \%)$ \\
\hline $\begin{array}{lll}- & \begin{array}{l}\text { Laparoscopic } \\
\text { drainage }\end{array} & \text { abscess } \\
\end{array}$ & $6(30 \%)$ \\
\hline - $\quad$ Bleeding control & $6(30 \%)$ \\
\hline \multicolumn{2}{|l|}{ Failure of first line, No (\%) } \\
\hline - No & $2(10 \%)$ \\
\hline - $\quad$ Yes & $18(90 \%)$ \\
\hline
\end{tabular}

Table 3: Management of the leak of the included patients.

Esophageal mega stent was inserted as second line treatment of leak in about two-thirds $(66.7 \%)$ of cases while the remaining underwent either laparoscopic abscess drainage (16.7\%), Roux en Y bypass $(11.1 \%)$ or were managed conservatively $(5.5 \%)$. The majority $(77.7 \%)$ of patients improved (Table 4). The remaining 4 patients were treated by esophageal mega stent (3rd line), one of them cured while 3 developed stent complications (Table 5). These three resistant cases underwent re stenting (4th line) where, one was controlled, one was failed to heal, and one patient died. The outstanding patient was treated by Roux en y and was failed (Table 6 ).

\begin{tabular}{|c|c|}
\hline Variables & $\begin{array}{l}\text { Patients } \\
(N=18)\end{array}$ \\
\hline \multicolumn{2}{|l|}{ Second-line, No (\%) } \\
\hline $\begin{array}{ll}\text { - } & \text { Esophageal mega stent }\end{array}$ & $12(66.7 \%)$ \\
\hline $\begin{array}{lll}- & \begin{array}{l}\text { Laparoscopic } \\
\text { drainage }\end{array} & \text { abscess } \\
\end{array}$ & $3(16.7 \%)$ \\
\hline - $\quad$ Conservative & $1(5.5 \%)$ \\
\hline - $\quad$ Roux en Y bypass & $2(11.1 \%)$ \\
\hline \multicolumn{2}{|l|}{ Failure of second-line, No (\%) } \\
\hline$-\quad$ No & $14(77.7 \%)$ \\
\hline - $\quad$ Yes & $4(22.2 \%)$ \\
\hline
\end{tabular}

Table 4: Management of the leak of the included patients.

\begin{tabular}{|c|c|}
\hline Variables & $\begin{array}{c}\text { Patients } \\
(N=4)\end{array}$ \\
\hline \multicolumn{2}{|l|}{ Third-line, No (\%) } \\
\hline - $\quad$ Esophageal mega stent & 4 \\
\hline \multicolumn{2}{|l|}{$3^{\text {rd }}$ line failure } \\
\hline - $\quad$ Yes & $3(75 \%)$ \\
\hline - $\quad$ No & $1(25 \%)$ \\
\hline
\end{tabular}

Table 5: Management of the leak of the included patients. 


\begin{tabular}{|c|c|}
\hline Variables & $\begin{array}{c}\text { Patients } \\
(\mathbf{N}=\mathbf{3})\end{array}$ \\
\hline \multicolumn{2}{|l|}{ Fourth-line, No (\%) } \\
\hline - $\quad$ Re-stenting & 3 \\
\hline \multicolumn{2}{|l|}{ Fifth-line, No (\%) } \\
\hline $\begin{array}{ll} & \text { Roux en } \mathrm{Y}\end{array}$ & $\mathbf{1}$ \\
\hline
\end{tabular}

Table 6: Management of the leak of the included patients.

The reported most common complications of leak management in the studied patients were failure of 1 st line management $(90 \%)$, stent migration in 3 $(15 \%)$, stent related ulcer and stricture in $1(5 \%)$ each. General complications were chest infection (20\%), deep vein thrombosis (10\%) (Table 7).

\begin{tabular}{|c|c|}
\hline Variables & $\begin{array}{l}\text { Patients } \\
(\mathbf{N}=\mathbf{2 0})\end{array}$ \\
\hline \multicolumn{2}{|l|}{ General No (\%) } \\
\hline - $\quad$ DVT & $2(10 \%)$ \\
\hline - $\quad \mathrm{PE}$ & $1(5 \%)$ \\
\hline - $\quad$ Chest infection & $4(20 \%)$ \\
\hline \multicolumn{2}{|l|}{ Local No (\%) } \\
\hline $\begin{array}{llll}\text { - } & \begin{array}{l}\text { Failure of } \\
\text { management }\end{array} & 1^{\text {st }} & \text { line } \\
\end{array}$ & $18(90 \%)$ \\
\hline - $\quad$ Stent migration & $3(15 \%)$ \\
\hline - $\quad$ Stent-related ulcer & $1(5 \%)$ \\
\hline - $\quad$ Stricture & $1(5 \%)$ \\
\hline
\end{tabular}

Table 7: Complications of management of leak of the included patients.

Table (8) shows outcomes of the leak of the included patients. Eighteen (90\%) survived while, 2 (10\%) died. The median time interval between closure and leak healing was 18 days. The median duration of hospital stay was 50 days.

\begin{tabular}{|c|c|}
\hline Variables & $\begin{array}{c}\text { Patients } \\
=20)\end{array}$ \\
\hline \multicolumn{2}{|l|}{ Morality, No (\%) } \\
\hline - $\quad$ Survived & $18(90 \%)$ \\
\hline - $\quad$ Dead & 2 \\
\hline \multicolumn{2}{|c|}{ Interval between closure and leak control in days } \\
\hline - $\quad$ Mean \pm SD & $44.2 \pm 24.36$ \\
\hline - $\quad$ Median (Range) & $43(7-98)$ \\
\hline \multicolumn{2}{|l|}{ Hospital stay in days } \\
\hline - $\quad$ Mean \pm SD & $51.9 \pm 13.2$ \\
\hline $\begin{array}{ll}- & \text { Median (Range) }\end{array}$ & $50(35-90)$ \\
\hline
\end{tabular}

Table 8: Outcomes of management of leak of the included patients

\section{DISCUSSION}

Laparoscopic sleeve gastrectomy has become the most popular bariatric surgery. It is characterized by being simple and highly effective in reducing weight, with comparable results to the gold standard laparoscopic "Roux-en-Y gastric bypass". ${ }^{11}$ Gastric leak is considered one of the main postoperative complication of SG, but to data, there were no standard therapeutic guidelines. ${ }^{12}$

The majority $(70 \%)$ of patients who developed leak in this study were females, with a mean age of 30.5 \pm 7.5 years and a mean BMI of $43.13 \pm 4.6 \mathrm{~kg} / \mathrm{m} 2$. Comparable results were reported by a large multicenter study where a higher prevalence of leak among women (68\%) and a mean BMI of $45.4 \mathrm{~kg} / \mathrm{m} 2$ were identified. ${ }^{13}$

Diagnosis of leak depends mainly on a high index of suspicion. The presence of tachycardia, unexplained fever, and abdominal pain should raise concerns about the possibility of leak. Furthermore, it has been agreed that tachycardia is the earliest and the most constant indicator of gastric leak. ${ }^{14}$ The role of postoperative contrast swallow examinations is not conclusive and should be done only in case of clinical suspicion. ${ }^{15}$ Abdominal computed tomography with contrast exhibits the best diagnostic accuracy. ${ }^{16}$ Actually, early detection of gastric leak is vital since it enables early intervention with more favorable patients' outcomes. ${ }^{17}$

In the current study, the majority ( $80 \%$ ) of leaks were diagnosed early within 1 to 4 days, $15 \%$ within 5 to 9 days, and only $5 \%$ were diagnosed later than 10 days. In comparison, Rebibo ${ }^{18}$ et al. have identified early onset leak within 7 days of GS operation in a lower number $(44.46 \%)$ of patients. Additionally, the median time interval between the surgery and leak diagnosis in this study was 3 days. Similarly, Moszkowicz ${ }^{19}$ et al. reported a median delay before diagnosis confirmation of 4.5 days. In contrast, a median time interval of 7 days has been reported. ${ }^{13}$

Despite stable line reinforcement was performed in half of the studied patients, all of them have developed leakage. This coincides with a systematic analysis that has not supported the role of suture reinforcement for leak prevention. ${ }^{20}$ Moreover, Bellanger ${ }^{21}$ et al. have reported absence of leak in 529 cases in which a 34 Fr bougie size was used without buttressing or over sewing the staple line. Though, there is still a debate regarding the optimum bougie size that enables effective weight loss and at the same time prevent the risk of leak. ${ }^{22}$

In the present study, intra operative leak test was used and $50 \%$ of patients showed positive results. Intraoperative diagnostic tests including methylene blue test has been previously used for leak detection. ${ }^{23}$ It has been assumed that intraoperative detection of leaks where tissues are viable enables good restapling or suturing to prevent postoperative leak. Though, negative tests do not exclude the possibility of leak. ${ }^{24}$ Furthermore, Sakran ${ }^{13}$ et al have not recommended routine use of intraoperative tests. 
The site of leak in this study was most commonly at GEJ $(50 \%)$ or beyond it $(25 \%)$ while, $4(20 \%)$ cases developed leak at incisura angularis. Similarly, Sakran et al. ${ }^{13}$ reported leak near GEJ in $75 \%$ of patients and identified that $89 \%$ of leaks were located in the proximal part of the gastric tube. ${ }^{20}$ This preferential site of leak was explained by reduced vascular perfusion of this part of stomach due to damage of blood vessels during sleeve procedure or due to increased pressure in the gastric tube due to pyloric conservations. $^{25}$

The management of leak post sleeve gastrectomy carries several controversies and difficulties in standardization of a clear treatment algorithm, due to the paucity of prospective randomized trials. But most studies demonstrated that the management plan should depends on the clinical evaluation, time of diagnosis and finally the location of the leak. ${ }^{25}$

The first line treatment of leak in this study included either laparoscopic abscess drainage (30\%), bleeding control $(30 \%)$, Pigtail drainage $(20 \%)$ or fistula repair and reinforcement (20\%). These interventions failed in $18(90 \%)$ cases. In agreement with this finding, Lorenzo ${ }^{26}$ et al. have concluded that surgical intervention before endoscopy delays treatment success. However, in unstable patients at presentation justify laparoscopic or open drainage and wash which may be associated with debridement and repair. ${ }^{27}$ Fistula repair especially after the $3^{\text {rd }}$ postoperative day is compromised by the presence of inflamed friable tissues and inability to identify the leak orifice clearly. ${ }^{20}$

In this work $18(90 \%)$ of patients were treated by esophageal mega stent as a second line leak management and it was successful in $14(77.77 \%)$ of them. In this regard, it has been reported that endoscopic management strategy of gastric leak after SG has been successful in $86 \%$ of cases. Generally, it includes either closure using a covered metal stent or endo-clips or internal drainage through naso-cystic drain and/or a double-pigtail stent. ${ }^{26}$ Furthermore, Southwell ${ }^{28}$ et al. concluded that the use of primary self-expanding metal stents across the leak site was safe and effective in treating $95 \%$ of sleeve leaks.

Treatment of chronic leak in this study involved reinserting a stent where 2 leaks resolved while one patient died and there was a resistant chronic leak that was treated by Roux en y gastric bypass which was not effective. The use of endoscopic stenting for treatment of chronic leak was successful in only 4 of 21 patients (19\%) in gastroenterology surgery division, Mayo clinic. However, they highlighted its role in ending ongoing sepsis and helps oral nutritional resuscitation of patients before operative correction. ${ }^{29}$ Surgical approach has been adopted as the only choice for treatment of chronic fistula after failure of endoscopic treatment. ${ }^{30}$ Additionally, the percentage of chronic fistula in these case series were lower than reported by Bruzzi ${ }^{31}$ et al. who documented 12 out of 57 patients.

Staple line leaks are difficult to manage and require significant resources in the form of surgical, radiological and endoscopic interventions; long hospital and intensive care stay and significant morbidity. This is associated with increased economic burden of the operation. ${ }^{32}$
In this study, the median time until healing of leak was 43 days and the median duration of hospital stay was 50 days, and finally 2 patients died with a mortality rate $10 \%$. Comparable to these outcomes, Rebibo ${ }^{18}$ et al. have reported $1.2 \%$ mortality rate and the median time to healing gastric leak was 84 days. Whereas, an international leak related mortality was $0.11 \% .33$ A recent study in a tertiary center in Qatar reported $0 \%$ mortality of patients complicated with leak and they recommended less urgency for extensive surgical intervention. ${ }^{34}$ The observed higher death rate in our series might be attributed to small sample size as study on 20 patients only.

\section{CONCLUSION}

Based on these findings, it could be concluded that most cases of gastric leak after SG could be successfully managed by endoscopic esophageal mega stent. However, persistent chronic leak is a serious complication associated with prolonged hospitalization, cost, and unfavorable outcomes. Furthermore, prevention of leak is of paramount importance through following particular considerations of SG.

\section{REFERENCES}

1. Alanezi H, Alshehri A, Alrobiea A, et al. The Causes, Prevention, and Management of Gastric Leakage after Laparoscopic Sleeve Gastrectomy: A Review Article. Journal of Metabolic and Bariatric Surgery. 2019;8(2):28-33.

2. Bamehriz F, Althuwaini S, Alobaid O, et al. Is body mass index $\geq 50 \mathrm{~kg} / \mathrm{m}(2)$ a predictor of higher morbidity for patients who have undergone laparoscopic sleeve gastrectomy? Saudi journal of anaesthesia. 2018;12(4):5558.

3. Abou Rached A, Basile M, El Masri H. Gastric leaks post sleeve gastrectomy: review of its prevention and management. World $\mathrm{J}$ Gastroenterol. 2014 Oct 14;20(38):13904-10.

4. Gagner M, Buchwald JN. Comparison of laparoscopic sleeve gastrectomy leak rates in four staple-line reinforcement options: a systematic review. Surg Obes Relat Dis. 2014;10(4):713-23.

5. Al-Kurd A, Grinbaum R, Abubeih A, et al. Not All Leaks Are Created Equal: a Comparison Between Leaks After Sleeve Gastrectomy and Roux-En-Y Gastric Bypass. Obes Surg. 2018;28(12):3775-82.

6. Antoine ar, Basile $\mathrm{M}$ and Masri H. Gastric leaks post sleeve gastrectomy: Review of its prevention and management. World journal of gastroenterology : WJG. 2014 10/14;20:1390410.

7. Silecchia G and Iossa A. Complications of staple line and anastomoses following laparoscopic bariatric surgery. Annals of gastroenterology. 2018;31(1):56-64. 
8. Sarkhosh K, Birch DW, Sharma A, et al. Complications associated with laparoscopic sleeve gastrectomy for morbid obesity: a surgeon's guide. Canadian journal of surgery Journal canadien de chirurgie. 2013;56(5):347-52.

9. Burgos $\mathrm{AM}$ and Braghetto I, Csendes $\mathrm{A}$, Maluenda F, Korn O, Yarmuch J, et al. Gastric leak after laparoscopic-sleeve gastrectomy for obesity. Obes Surg. 2009;19(12):1672-7.

10. Musella M, Milone M, Bianco P, et al. Acute Leaks Following Laparoscopic Sleeve Gastrectomy: Early Surgical Repair According to a Management Algorithm. J Laparoendosc Adv Surg Tech A. 2016;26(2):85-91.

11. Gagner $\mathrm{M}$, Deitel $\mathrm{M}$, Erickson $\mathrm{AL}$, et al. Survey on laparoscopic sleeve gastrectomy (LSG) at the Fourth International Consensus Summit on Sleeve Gastrectomy. Obes Surg. 2013;23(12):2013-7.

12. Giuliani A, Romano L, Marchese M, et al. Gastric leak after laparoscopic sleeve gastrectomy: management with endoscopic double pigtail drainage. A systematic review. Surg Obes Relat Dis. 2019;15(8):1414-9.

13. Sakran N, Goitein D, Raziel A, Keidar A, et al Gastric leaks after sleeve gastrectomy: a multicenter experience with 2,834 patients. Surg Endosc. 2013;27(1):240-5.

14. Botaitis SJCR. Prevention and Management of Sta-ple Line Leaks after Laparoscopic Sleeve Gastrectomy.(2018) J Anesth Surg 5 (1): 95102. J Anesth Surg. 2018;5(1):2377-1364.18.

15. Chivot C, Rebibo L, Robert B, et al. Value of routine upper gastrointestinal swallow study after laparoscopic sleeve gastrectomy. Surg Obes Relat Dis. 2017;13(5):758-65.

16. Alharbi SR. Computed Tomography-based Diagnosis of Post-laparoscopic Sleeve Gastrectomy Gastric Leak. Journal of clinical imaging science. 2020;10:8-.

17. Lainas $\mathrm{P}$, Tranchart $\mathrm{H}$, Gaillard $\mathrm{M}$, et al. Prospective evaluation of routine early computed tomography scanner in laparoscopic sleeve gastrectomy. Surg Obes Relat Dis. 2016;12(8):1483-90.

18. Rebibo L, Bartoli E, Dhahri A, et al. Persistent gastric fistula after sleeve gastrectomy: an analysis of the time between discovery and reoperation. Surg Obes Relat Dis. 2016;12(1):84-93.

19. Moszkowicz D, Arienzo R, Khettab I, et al. Sleeve gastrectomy severe complications: is it always a reasonable surgical option? Obes Surg. 2013;23(5):676-86.

20. Aurora AR, Khaitan L and Saber AA. Sleeve gastrectomy and the risk of leak: a systematic analysis of 4,888 patients. Surg Endosc. 2012;26(6):1509-15.

21. Bellanger DE and Greenway FL. Laparoscopic sleeve gastrectomy, 529 cases without a leak: short-term results and technical considerations. Obes Surg. 2011;21(2):146-50.

22. Yuval JB, Mintz Y, Cohen MJ, et al. The effects of bougie caliber on leaks and excess weight loss following laparoscopic sleeve gastrectomy. Is there an ideal bougie size? Obes Surg. 2013;23(10):1685-91.

23. Deitel M, Crosby RD and Gagner M. The First International Consensus Summit for Sleeve Gastrectomy (SG), New York City, 2007. Obes Surg. 2008;18(5):487-96.

24. Casella G, Soricelli E, Rizzello M, et al. Nonsurgical treatment of staple line leaks after laparoscopic sleeve gastrectomy. Obes Surg. 2009;19(7):821-6.

25. Perez M, Brunaud L, Kedaifa S, et al. Does anatomy explain the origin of a leak after sleeve gastrectomy? Obes Surg. 2014;24(10):1717-23.

26. Lorenzo D, Guilbaud T, Gonzalez JM, et al. Endoscopic treatment of fistulas after sleeve gastrectomy: a comparison of internal drainage versus closure. Gastrointest Endosc. 2018;87(2):429-37.

27. Wahby M, Salama AF, Elezaby AF, et al. Is routine postoperative gastrografin study needed after laparoscopic sleeve gastrectomy? Experience of 712 cases. Obes Surg. 2013;23(11):1711-7.

28. Southwell T, Lim TH and Ogra R. Endoscopic Therapy for Treatment of Staple Line Leaks Post-Laparoscopic Sleeve Gastrectomy (LSG): Experience from a Large Bariatric Surgery Centre in New Zealand. Obes Surg. 2016;26(6):1155-62.

29. Puig CA, Waked TM, Baron TH, et al. The role of endoscopic stents in the management of chronic anastomotic and staple line leaks and chronic strictures after bariatric surgery. Surg Obes Relat Dis. 2014;10(4):613-7.

30. Nedelcu M, Danan M, Noel P, et al. Surgical management for chronic leak following sleeve gastrectomy: Review of literature. Surg Obes Relat Dis. 2019;15(10):1844-9.

31. Bruzzi M, Douard R, Voron T, et al. Open total gastrectomy with Roux-en-Y reconstruction for a chronic fistula after sleeve gastrectomy. Surg Obes Relat Dis. 2016;12(10):1803-8.

32. Nedelcu M, Manos T, Gagner M, et al. Cost analysis of leak after sleeve gastrectomy. Surg Endosc. 2017;31(11):4446-50.

33. Parikh M, Issa R, McCrillis A, et al. Surgical strategies that may decrease leak after laparoscopic sleeve gastrectomy: a systematic 
review and meta-analysis of 9991 cases. Ann Surg. 2013;257(2):231-7.

34. Bashah $\mathrm{M}$, Khidir $\mathrm{N}$ and El-Matbouly $\mathrm{M}$. Management of leak after sleeve gastrectomy: outcomes of 73 cases, treatment algorithm and predictors of resolution. Obesity Surgery. 2020;30(2):515-20. 